\title{
LA PROTECCIÓN DEL MENOR INFRACTOR ANTE LOS MEDIOS DE COMUNICACIÓN
}

Jorge Jiménez Martín

Magistrado - Especialista Menores

Profesor del Área de Instrucción de la Escuela Judicial

\begin{abstract}
RESUMEN
Junto al creciente fenómeno de transparencia judicial existen prácticas frecuentes en las informaciones periodísticas que atentan contra garantías fundamentales propias del proceso penal, pues más allá de informar objetivamente, se tiende a introducir en la noticia, ya sea de forma implícita o expresa, la opinión del medio o del periodista de cómo se debe fallar un asunto sub-judice, sea a favor del acusado/a, o en su contra, presionando a los Tribunales a que resuelvan el asunto en el sentido que preconiza el medio, o bien vulnerando su derecho a la intimidad, el honor y la propia imagen al presentar a personas sometidas a procesos como culpables, antes de que exista una condena en firme. Este trabajo intenta dar respuesta a todas estas polémicas
\end{abstract}

\begin{abstract}
Close to the increasing phenomenon of judicial transparency frequent practices exist in the journalistic information that commit an outrage against fundamental own guarantees of the penal process, so beyond reporting objectively, it is tended to introduce in the news, already be of implicit or express form, the opinion of the way or of the journalist of how it is necessary to to trump a matter sub-judice, be in favour of the marked / marked one, or in his against, pressing to the Courts to which they solve the matter in the sense that praises the way, or damaging his right to the intimacy, the honor and the own image on having presented persons submitted to processes as culprits, before a sentence exists in road surface. This work tries to give response to all these polemics
\end{abstract}




\section{A. PLANTEAMIENTO.}

En nuestra sociedad venimos asistiendo a una continua, amplia y precisa cobertura de los procesos penales que se instruyen y celebran en nuestros Tribunales. Cierto es que en muchas ocasiones la atracción de los medios de comunicación la centra la posición social o profesional de quien se ve inmerso en ellos ${ }^{1}$, pero en otras han sido los propios hechos que se le imputan al acusado -sea por su gravedad o por la repulsa que socialmente generan ${ }^{2}$ - o las circunstancias de la víctima de los mismos los elementos que han atraído el interés de la sociedad y una, en muchos casos, desmesurada cobertura de los medios de comunicación.

Esta difusión mediática del proceso penal no puede considerarse apriorísticamente perjudicial, ni debe rechazarse, pues supone transparencia y es muy conveniente dentro de una sociedad democrática, más aún cuando nuestra propia Constitución ampara tal publicidad en la Administración de Justicia en su artículo 120.133. Dicha previsión constitucional es una auténtica conquista social, propia del Estado Social y Democrático de Derecho en el que nos constituimos ${ }^{4}$, en contraposición a la llamada "justicia de gabinete 5 o al secretismo profesional que regía en otras épocas en la Justicia, y representa una auténtica garantía de los derechos fundamentales del ser humano frente al arbitrio judicial y eventuales manipulaciones gubernamentales en la constitución y funcionamiento de la judicatura. A su vez, no debemos olvidar que implica un auténtico instrumento de legitimación de los Tribunales frente a los ciudadanos y ciudadanas, pues la posibilidad de control popular sobre la Administración de Justicia genera confianza en el público sobre las actuaciones del Poder Judicial ${ }^{6}$ y mejora

\footnotetext{
${ }^{1}$ Recientemente hemos podido contemplar el amplio seguimiento que los medios de comunicación han hecho a los juicios orales del Juez Baltasar Garzón o del ex Presidente de la Generalitat Valenciana, Francisco Camps. Y es notoria la trascendencia y el seguimiento de la reciente imputación del Duque de Palma, Iñaki Urdangarín, por señalar los casos con mayor eco mediático.

${ }^{2}$ De esta forma, los delitos contra la vida, la integridad física, y la libertad e indemnidad sexuales son los que mayor eco tienen en los medios de comunicación, así como los que afectan, sea activa o pasivamente, a menores o mujeres.

${ }^{3}$ Artículo 120.1 CE: "Las actuaciones judiciales serán públicas, con las excepciones que prevean las Leyes de procedimiento".

${ }^{4}$ Artículo 1.1 C.E..

${ }^{5}$ STS, Sala 2a 10 de Diciembre de 2.010. ROJ: STS 7056/2010

${ }^{6}$ Originalmente, la garantía de publicidad se pensó para que fuera satisfecha con la presencia directa de los ciudadanos/as en la sala de vistas observando el desarrollo del proceso, lo que se denomina publicidad inmediata. No obstante, la complejidad del mundo globalizando en el que vivimos hace que la forma de dar pleno cumplimiento a esta garantía sea a través de una publicidad mediata, es decir, la que se logra difundiendo más allá de la sala de vistas.
} 
considerablemente su imagen pública. Y ello, aún cuando controvertidas decisiones judiciales, merman la imagen social de la justicia y su aceptación.

Sin embargo, junto al creciente fenómeno de transparencia judicial existen prácticas frecuentes en las informaciones periodísticas que atentan contra garantías fundamentales propias del proceso penal, pues más allá de informar objetivamente, se tiende a introducir en la noticia, ya sea de forma implícita o expresa, la opinión del medio o del periodista de cómo se debe fallar un asunto sub-judice, sea a favor del acusado/a, o en su contra, presionando a los Tribunales a que resuelvan el asunto en el sentido que preconiza el medio, o bien vulnerando su derecho a la intimidad, el honor y la propia imagen al presentar a personas sometidas a procesos como culpables, antes de que exista una condena en firme. Asistimos a auténticos juicios paralelos suscitados y alimentados por nuestros medios de comunicación, donde no solo se vulnera la presunción constitucional de inocencia ${ }^{7}$ que a toda persona ampara hasta que recaiga sentencia firme sino que se violenta, anticipando en el tiempo una sentencia social, en la casi totalidad de los casos condenatoria, a la que nada afectará una posterior sentencia absolutoria dictada por quien es legítimo y constitucional titular de dicha potestad. De esta forma, la presunción de inocencia queda vulnerada, y el daño causado a quien se vio sometido a un proceso penal resulta prácticamente irreparable.

Esta situación que describimos reviste mayor gravedad en el caso de los menores de edad que cometen algún hecho susceptible de responsabilidad penal, y que se ven sometidos por ello a un proceso penal. En este sentido, la implicación de menores en hechos delictivos cometidos por adultos ${ }^{8}$ presenta casos de especial trascendencia mediática en los que se evidencia un ataque frontal al menor infractor y los principios legales internacionales y nacionales que rigen en nuestro sistema jurídico. Partiendo de que el derecho penal de menores reviste unas características y una configuración radicalmente contrapuesta al derecho penal de adultos, no solo por prescripción legal sino por vinculación de los acuerdos y convenios internacionales ratificados por España, en el que prima y reina como principio fundamental el interés superior del menor ${ }^{9}$, con

\footnotetext{
${ }^{7}$ Artículo 24.2 C.E.: "Asimismo, todos tienen derecho al Juez ordinario predeterminado por la Ley, a la defensa y a la asistencia de letrado, a ser informados de la acusación formulada contra ellos, a un proceso público sin dilaciones indebidas y con todas las garantías, a utilizar los medios de prueba pertinentes para su defensa, a no declarar contra sí mismos, a no confesarse culpables y a la presunción de inocencia".

${ }^{8}$ El caso paradigmático y reciente ha sido la implicación de un menor en el denominado Caso Marta del Castillo, celebrándose dos juicios orales, en la jurisdicción de menores y de adultos, unidos al juicio paralelo social y de los medios de comunicación.

9 Señala RIVERO FERNÁNDEZ, F. en su libro "El interés del menor", (Dykinson, Madrid 2.000) que el interés superior del menor tampoco "supone un trato de favor compensatorio de un previo e injusto desequilibrio contrario a él, pues aquel principio no afecta sólo a los menores desamparados, maltratados o desafortunados, sino que es aplicable a todos los menores. Se trata, sencillamente, de hacerles justicia en su vertiente existencial y de garantizarle su status de persona y los bienes y derechos
} 
la posibilidad de imponer de forma flexible medidas de naturaleza educativosancionadora. Es más, casi al mismo nivel del castigo por la acción delictiva cometida, se pretende la reeducación del menor con el fin de que pueda integrarse en la vida social. Ello hace que la publicidad que constitucionalmente se predica de las actuaciones judiciales debiera revestir mayores matizaciones en la jurisdicción penal de menores. Si en la relación entre medios de comunicación y proceso penal se produce una colisión entre la libertad de información y la presunción de inocencia, en el ámbito de la jurisdicción de menores afecta también al interés del menor y a la protección de la infancia y de la juventud, teniendo una mayor trascendencia, tal y como posteriormente desarrollaremos.

A ello pretendemos dedicar este trabajo, reflexionando acerca de la protección audiovisual del menor que comete algún hecho susceptible de responsabilidad penal, conforme a lo dispuesto en la Ley 5/2000, de 12 de Enero, reguladora de la Responsabilidad Penal del Menor (LORPM). En el marco del proyecto de investigación de excelencia sobre la "Protección integral de los menores en el ámbito audiovisual" pretendemos analizar el marco normativo vigente, la problemática que actualmente se suscita, y extraer algunas conclusiones que pudieran ser tenidas en cuenta por el legislador y los actores que intervienen en este proceso de “diálogo" informativojudicial, no solo a nivel deontológico sino también como recomendación de lege ferenda. Vaya de inicio nuestra reflexión previa: Si hemos ratificado y asumido la normativa internacional relativa a los menores, a la delincuencia juvenil y a su tratamiento, y hemos desarrollado una ley para la jurisdicción de menores -de acuerdo a dicha normativa- en la que priman el interés superior del menor y la finalidad educativa de las medidas sancionadoras, con gran éxito de aplicación y reinserción, la protección audiovisual e informativa de los menores infractores debería ser total, evitando juicios paralelos, que se conozca la identidad y circunstancias de los menores afectados, y que las víctimas y sus familiares se resarcieran del daño causado a través de la utilización de los medios de comunicación.

\section{B. MARCO NORMATIVO EN EL ÁMBITO DE LA JURISDICCIÓN PENAL DE MENORES.}

La información judicial cuenta en nuestro país con una regulación que pretende equilibrar principios tan diversos como el respeto a la autoridad judicial, la preservación de su independencia, el derecho a la presunción de inocencia, la publicidad del proceso

\footnotetext{
fundamentales de la misma que por su mera calidad de persona le corresponden, si bien adecuados todos ellos a su situación de menor de edad (...) inepto todavía para ejercitarlos a ciertas edades y necesitados, sin embargo, de particular protección para que su propia entidad e identidad personal no se frustre, y llegue a ser mañana un ciudadano activo perfectamente integrado en la sociedad". Considera que "el principio del interés del menor o del favor minoris (...) no significa dispensarle un trato anormalmente favorable en el sentido de discriminatorio (positivo) sino de tratarle justamente adecuando a su persona (menor de edad) los derechos y normas que como persona, no más, le corresponden.
} 
y el derecho a la información. Nos interesa centrarnos en este momento en las previsiones legislativas y jurisprudenciales que, tanto a nivel internacional como nacional, contemplan una posible protección del menor infractor respecto de las informaciones que los medios de comunicación puedan transmitir a la sociedad sobre su identidad, vida privada, o circunstancias del hecho por ellos presuntamente cometido ${ }^{10}$.

\section{Perspectiva internacional.}

Si acudimos a la normativa internacional encontramos, como clave de bóveda del sistema, la Convención sobre los Derechos del Niño, de 20 de Noviembre de $1.989^{11}$. El artículo 3.1 parte de una declaración general al señalar que "en todas las medidas concernientes a los niños que tomen las instituciones públicas o privadas de bienestar social, los tribunales, las autoridades administrativas o los órganos legislativos, una consideración primordial a que se atenderá será el interés superior del niño”.

Con mayor detalle y relevancia para la cuestión que nos ocupa, el artículo 8.1 incide sobre la preservación de la identidad del menor y señala que "los Estados partes se comprometen a respetar el derecho del niño a preservar su identidad, incluidos la nacionalidad, el nombre y las relaciones familiares de conformidad con la ley sin injerencias ilícitas”. Y el artículo 16 destaca que "ningún niño será objeto de injerencias arbitrarias o ilegales en su vida privada, su familia, su domicilio o su correspondencia, ni de ataque ilegales a su honra y a su reputación. El niño tiene derecho a la protección de la ley contra esas injerencias o ataques”.

Debemos resaltar igualmente que, no obstante, la Convención reconoce la importante función que desempeñan los medios de comunicación para promover el bienestar y la salud del menor (artículo 17.1).

Por lo que se refiere de forma específica al menor infractor que se ve vinculado a un proceso penal, la propia Convención en su artículo 40.2.b).vii) señala que “... los Estados partes garantizarán, en particular: b) que todo niño del que se alegue ha infringido las leyes penales o a quien se acuse de haber infringido esas leyes se le

\footnotetext{
${ }^{10}$ A la hora de reflexionar sobre la protección del menor infractor ante los medios de comunicación existen dos momentos temporales de especial trascendencia. El primero, que abarca hasta el dictado de una sentencia firme, sea o no condenatoria, en el que constitucionalmente rige con toda su fuerza la presunción de inocencia. A esta fase nos referimos de forma específica en estas reflexiones. La segunda, una vez recaída sentencia firme, y específicamente condenatoria, en la que se declara la responsabilidad penal del menor. Es cierto que en esta fase ya no rige la presunción de inocencia, totalmente desvirtuada por la prueba de cargo presentada ante el Tribunal, pero no es menos cierto que la protección del menor ante los medios de comunicación reviste igual importancia y trascendencia, dados los principios que rigen en la jurisdicción. No obstante, sobre esta reflexión nos extenderemos en nuestras conclusiones.

${ }^{11}$ Ratificada por España el 30 de Noviembre de 1.990 (BOE, № 313, de 31 de Diciembre de 1.990).
} 
garantice, por lo menos, lo siguiente: vii) Que se respetará plenamente su vida privada en todas las fases del procedimiento (penal)."

Profundizando en el ámbito de la jurisdicción de menores, existen distintos textos normativos que contemplan la protección del menor infractor en relación a su identidad, imagen, reputación y respecto a los medios de comunicación. Así, las Reglas Mínimas de las Naciones Unidas adoptadas por la Asamblea General en resolución 40/33, de 28 de Noviembre de 1.985, las conocidas como "Reglas de Beijing", contemplan en su regla octava la protección de la intimidad: "8.1 Para evitar que la publicidad indebida o el proceso de difamación perjudiquen a los menores, se respetará en todas las etapas el derecho de los menores a la intimidad. 8.2 En principio, no se publicará ninguna información que pueda dar lugar a la individualización de un menor delincuente”12.

Por último, el Comité de Ministros del Consejo de Europa, en su Recomendación (2003) 20, de 24 de Septiembre, sobre nuevas vías para el tratamiento de la delincuencia juvenil y el papel de la justicia juvenil, en su punto VI.25, concreta que "cualquier información sobre procesos a menores deberá preservar la identidad y la imagen del menor implicado, y que, excluye siempre la presencia de medios de comunicación en la audiencia con el menor. Algo que si afecta al delincuente, con mucho mayor motivo debe mantenerse con el menor víctima”.

Conviene destacar aquí algunos pronunciamientos jurisprudenciales que marcan el camino y la línea de dicha protección. Destaca entre ellos la sentencia del Tribunal Europeo de Derechos Humanos (TEDH) de 16 de Diciembre de 1.999 (el llamado caso “niños de Liverpool”) ${ }^{13}$ en el que se condenó al Reino Unido por violación del derecho a un proceso justo por haber permitido que los menores acusados fueran sometidos a un proceso público, siendo ubicados en un lugar de la sala en la que podían ser observados por el público que manifestaba una actitud hostil hacia ellos y por los medios de comunicación. Se conocieron sus nombres y se divulgaron sus fotografías, teniendo también acceso los medios de comunicación a los informes psicológicos previos al juicio y a los que se realizaron durante su internamiento; hasta el punto de necesitar un cambio de identidad, entre otras medidas, para asegurar de algún modo su reinserción al finalizar las medidas sancionadoras impuestas.

También resulta interesante la sentencia dictada en el asunto Gutiérrez Suárez v. España el 1 de Junio de 2.010, donde el TEDH recuerda que, por razón de los "deberes y responsabilidades" derivados del ejercicio de la libertad de expresión, la garantía que

\footnotetext{
${ }^{12}$ En el mismo sentido consta en el art. 14.1 del Pacto Internacional de Derechos Civiles y Políticos de 19 de Diciembre de 1966, y en el art. 40 de la Convención sobre los Derechos del Niño de 20 de Noviembre de 1989.

${ }^{13}$ Robert Thompson y Jon Venables, de diez años, sustrajeron del cuidado de su madre a un niño de dos años, James Bulger, en la localidad de Liverpool en 1.993, asesinándolo al cabo de unas horas.
} 
el artículo 10 proporciona a los periodistas con respecto a la presentación de informes sobre cuestiones de interés general queda sujeta a la condición de que actúen de buena fe con la finalidad de proporcionar información veraz y confiable con pleno respeto de la deontología periodística. Con la finalidad de evaluar la justificación de una afirmación controvertida, es necesario distinguir entre información de hechos y juicios de valor. Si bien los primeros pueden demostrarse, en el caso de los segundos no puede demostrarse su exactitud. La caracterización de una exposición de hechos o juicios de valor depende, principalmente, del margen de apreciación de las autoridades nacionales, en particular de los órganos jurisdiccionales internos. Sin embargo, incluso en los supuestos en los que una declaración equivale a un juicio de valor, debe basarse en una base fáctica suficiente, de lo contrario sería excesiva

\section{Perspectiva nacional.}

Al afrontar el estudio de la regulación del derecho a la información y la protección del menor destacan en nuestra Constituciones las previsiones del artículo 20.4, que coloca la protección de la juventud y la infancia como límite específico al derecho a la información, y del artículo 39.4, que declara que los niños gozarán de la protección prevista en los acuerdos internacionales que velan por sus derechos.

En nuestra normativa interna, la regulación general viene contemplada en la Ley Orgánica 1/1996, de Protección Jurídica del Menor, que con fundamento en la protección jurídica del menor que exige nuestra Constitución (artículo 39) como principio rector de la política social y económica, dota a los menores de un completo y adecuado marco jurídico de protección, en consonancia con los Tratados Internacionales ratificados.

Señala su artículo 2, como principio general, que "en la aplicación de la presente Ley primará el interés superior de los menores sobre cualquier otro interés legítimo que pudiera concurrir. Asimismo, cuantas medidas se adopten al amparo de la presente Ley deberán tener un carácter educativo”.

Sin embargo, es el artículo 4 el que desarrolla todo lo concerniente al derecho al honor, a la intimidad y a la propia imagen. Partiendo del reconocimiento de tal derecho en el apartado primero (" 1 . Los menores tienen derecho al honor, a la intimidad personal y familiar y a la propia imagen. Este derecho comprende también la inviolabilidad del domicilio familiar y de la correspondencia, así como del secreto de las comunicaciones”), y de lo que debe entenderse como intromisión ilegítima en tales derechos en el apartado tercero ("cualquier utilización de su imagen o su nombre en los medios de comunicación que pueda implicar menoscabo de su honra o reputación, o que sea contraria a sus intereses incluso si consta el consentimiento del menor o de sus representantes legales"), determina en su apartado segundo que "la difusión de información o la utilización de imágenes o nombre de los menores en los medios de comunicación que puedan implicar una intromisión ilegítima en su intimidad, honra o reputación, o que sea contraria a sus intereses, determinará la intervención del 
Ministerio Fiscal ${ }^{14}$, que instará de inmediato las medidas cautelares y de protección previstas en la Ley y solicitará las indemnizaciones que correspondan por los perjuicios causados". La Circular de la Fiscalía General del Estado 1/2000, de 18 de Diciembre, sobre criterios de aplicación de la LO 5/2000 pone de manifiesto la obligación del Fiscal de "convertirse en un inflexible protector de la intimidad del menor”. La propia Instrucción 2/2006, de 15 de Marzo de la Fiscalía General del Estado, sobre el Fiscal y la protección del derecho al honor, intimidad y propia imagen de los menores, señala que el Fiscal no tiene una posición de subsidiariedad sino que podrá actuar aun cuando el menor esté representado por sus progenitores, incluso aun contra la voluntad de éstos o del menor. Sin duda alguna, y en clara consonancia con los principios de protección que rigen a la infancia, constituye en garante de cualquier atentado al honor, intimidad o imagen de los menores, al Ministerio Fiscal. La referida Instrucción matiza tal legitimación al señalar que dicha amplia legitimación deberá en todo caso utilizarse con prudencia, ponderando todos los intereses en conflicto. Considera que habrá de valorarse especialmente si la intromisión ha contado o no con el consentimiento del menor maduro o de los progenitores del menor no maduro. Deberá también valorarse si pese a tratarse de una intromisión no consentida, el menor maduro o sus representantes legales se oponen motivadamente a que el Fiscal ejercite las acciones en protección de estos derechos. Habrá de ser excepción la intervención autónoma del Fiscal cuando el menor afectado tenga progenitores en pleno uso de las facultades inherentes a la patria potestad, y que -sin que concurra conflicto de intereses con el menor sean contrarios a que se entablen acciones en defensa del mismo.

Lo que sorprende en el caso de los menores infractores, al reunir en la misma persona las condiciones de instructor y acusador en la causa penal y defensor de su honor, imagen e intimidad, con las disfunciones o aparentes contradicciones que pudieran darse por ello ${ }^{15}$, y ello aunque se alegue que será el Fiscal de Protección y no el de Menores el encargado de reclamar dicha protección. Es más, en los supuestos de delitos graves, como los que están en mente de la sociedad al analizar el funcionamiento de la LORPM, no será socialmente aceptado ni entendido que quien ejerce la acusación desempeñe un papel de protección del menor infractor. Así parece haberlo entendido la Fiscalía General del Estado en su Circular 9/2011, de 16 de Noviembre, al destacar la función que los Fiscales Delegados de Menores pueden asumir como portavoces de la Fiscalía ante los medios de comunicación en materia de menores, conforme a la previsión de la Instrucción $n^{0} 3 / 2008$, por la demanda social de información en asuntos de menores y ante la necesidad de evitar la aparición de noticias que, carentes de rigor, generen desinformación y alarma, debiendo desempeñarse esta función prestando

\footnotetext{
${ }^{14}$ Señala el artículo 4.4 de la Ley Orgánica 1/1996, de Protección Jurídica del Menor: "Sin perjuicio de las acciones de las que sean titulares los representantes legales del menor, corresponde en todo caso al Ministerio Fiscal su ejercicio, que podrá actuar de oficio o a instancia del propio menor o de cualquier persona interesada, física, jurídica o entidad pública".

${ }^{15}$ Son escasas las actuaciones protectoras realizadas en este sentido, y casi inexistentes las que hayan tenido trascendencia pública -lo que redunda en el éxito de la actuación, pues de conocerse sea consciente el lector de que estaríamos en un constante círculo vicioso-, aún cuando existen algunas muy puntuales y que por ello quedan como meramente testimoniales. Es más, las conocidas han venido a prestar esa protección de forma tangencial o indirecta, y sirva como ejemplo las actuaciones desarrolladas por el Ministerio Fiscal ante la aparición de una menor, presentada como pareja del declarado autor de la muerte de Marta del Castillo, en un programa de televisión.
} 
especial cuidado a la preservación de la intimidad de los menores afectados. Lo que ello sugiere y pone de manifiesto, es el conflicto y la tensión entre derecho a la información y protección del menor infractor. No obstante, quedémonos con lo de bueno que dicha doble atribución puede tener para la protección del menor, al ser el Ministerio Fiscal quien debe velar por dichos derechos desde el primer momento en el que se incoa el procedimiento penal de menores.

Junto a la labor del Ministerio Fiscal en la protección que analizamos, reviste especial importancia la que el artículo 11 de la Ley de Protección Jurídica del Menor atribuye a los poderes públicos, que deberán facilitar a los menores la asistencia adecuada para el ejercicio de sus derechos (artículo 11.1), y cuya actuación se regirá por los siguientes principios rectores (artículo 11.2): la supremacía del interés del menor; el mantenimiento del menor en el medio familiar de origen salvo que no sea conveniente para su interés; su integración familiar y social; la prevención de todas aquellas situaciones que puedan perjudicar su desarrollo personal; sensibilizar a la población ante situaciones de indefensión del menor; promover la participación y la solidaridad social; y la objetividad, imparcialidad y seguridad jurídica en la actuación protectora garantizando el carácter colegiado e interdisciplinar en la adopción de medidas.

La LORPM contempla someramente la protección del menor ante los medios de comunicación. En primer lugar, atribuye en su artículo 6 al Ministerio Fiscal "la defensa de los derechos que a los menores reconocen las leyes, así como la vigilancia de las actuaciones que deban efectuarse en su interés y la observancia de las garantías del procedimiento, para lo cual dirigirá personalmente la investigación de los hechos y ordenará que la policía judicial practique las actuaciones necesarias para la comprobación de aquéllos y de la participación del menor en los mismos, impulsando el procedimiento". Contempla la posibilidad de declarar secreto el expediente de menores, en paralelismo con lo que ocurre en el sistema penal de adultos, señalando en el artículo 24 que "el Juez de Menores, a solicitud del Ministerio Fiscal, del menor o de su familia, o de quien ejercite la acción penal, podrá decretar mediante auto motivado el secreto del expediente, en su totalidad o parcialmente, durante toda la instrucción o durante un período limitado de ésta. No obstante, el letrado del menor y quien ejercite la acción penal deberán, en todo caso, conocer en su integridad el expediente al evacuar el trámite de alegaciones. Este incidente se tramitará por el Juzgado en pieza separada". Y, finalmente, regula la no publicidad del juicio en el artículo $35.2^{16}$, pues "el Juez podrá acordar, en interés de la persona imputada o de la víctima, que las sesiones no sean públicas y en ningún caso se permitirá que los medios de comunicación social obtengan o difundan imágenes del menor ni datos que permitan su identificación" $"$.

Lo que resulta más trascendente, vista la realidad de los casos que han generado más alarma y debate social, es que el artículo 35.3 dispone que "quienes ejerciten la acción

\footnotetext{
${ }^{16}$ Dicho artículo fue fruto de la STC 36/91, de 14 de Febrero, que ya se decantó por la posibilidad de restringir la publicidad en el proceso de menores.

${ }^{17}$ El artículo 232 de la LOPJ, por su parte, establece que las actuaciones judiciales serán públicas, con las excepciones que prevean las leyes de procedimiento y que excepcionalmente, por razones de orden público y de protección de los derechos y libertades, los Jueces y Tribunales, mediante resolución motivada, podrán limitar el ámbito de la publicidad y acordar el carácter secreto de todas o parte de las actuaciones.
} 
penal en el procedimiento regulado en la presente Ley, habrán de respetar rigurosamente el derecho del menor a la confidencialidad y a la no difusión de sus datos personales o de los datos que obren en el expediente instruido, en los términos que establezca el Juez de Menores. Quien infrinja esta regla será acreedor de las responsabilidades civiles y penales a que haya lugar". Sin embargo, hasta la fecha y en los casos con más trascendencia social, la previsión legal para que no se ha hecho efectiva, existiendo cierta permisividad. Más aún cuando quienes participan o colaboran de alguna forma, aún incidental, con esa difusión, es la propia víctima o los perjudicados por el delito.

Más recientemente, la Ley 7/2010, de 31 de Marzo, General de la Comunicación Audiovisual $^{18}$, regula la comunicación audiovisual de cobertura estatal y establece las normas básicas en materia audiovisual sin perjuicio de las competencias reservadas a las Comunidades Autónomas y a los Entes Locales en sus respectivos ámbitos. Nos interesa de forma especial la regulación de los derechos del menor que realiza en su artículo 7, declarando en su apartado primero que "los menores tienen el derecho a que su imagen y voz no sean utilizadas en los servicios de comunicación audiovisual sin su consentimiento o el de su representante legal, de acuerdo con la normativa vigente. En todo caso, está prohibida la difusión del nombre, la imagen u otros datos que permitan la identificación de los menores en el contexto de hechos delictivos o emisiones que discutan su tutela o filiación”. Tras regular en sus apartados segundo y tercero la prohibición de emisión de contenidos audiovisuales o comunicaciones comerciales que les puedan perjudicar, fijando distintos horarios de emisión, en su apartado cuarto dispone que "la autoridad audiovisual competente promoverá entre los prestadores del servicio de comunicación audiovisual televisiva el impulso de códigos de conducta en relación con la comunicación comercial audiovisual inadecuada.....”,

Esta ley crea el Consejo Estatal de Medios Audiovisuales (artículo 44), con personalidad jurídica propia y plena capacidad de obrar, y adscrito al Ministerio de la Presidencia. Resulta especialmente relevante que la Ley le atribuya entre sus fines y funciones (artículos 45.b) y 46.1.n)) la plena eficacia de los derechos y obligaciones establecidos en esta Ley: en especial todo lo referente al menor. Las facultades que le atribuye la ley, artículo 47, son muy amplias para los fines de protección de los menores que aquí nos interesan, abarcando desde dictar disposiciones, realizar requerimientos de datos y de cese de actividades, adoptar medidas e incluso ejercer la potestad sancionadora en los supuestos legalmente contemplados (artículos 55 y ss.). Destaca especialmente la previsión legal, como infracción muy grave (artículo 57.4), de la difusión del nombre, la imagen u otros datos que permitan la identificación de los menores en el contexto de hechos delictivos o en emisiones que discutan su tutela 0 filiación; como infracción grave (artículo 58.3), la vulneración de la prohibición, y en su caso, de las condiciones de emisión de contenidos perjudiciales para el menor, previstas

\footnotetext{
${ }^{18}$ Supone la transposición de la Directiva 2007/65/CE de Servicios de Comunicación Audiovisual del Parlamento Europeo y del Consejo de 11 de diciembre del 2007.
} 
en el artículo 7.2. ${ }^{19}$. En todo caso, prevé el castigo de las infracciones muy graves con multa de 500.001 hasta 1.000 .000 de euros para los servicios de comunicación audiovisual televisiva y de 100.001 a 200.000 para los radiofónicos, para los prestadores del servicio de comunicación electrónica y para los prestadores de servicio de catálogo de programas, además de poder ser sancionadas con la revocación de la licencia para prestar el servicio de comunicación audiovisual por ondas hertzianas terrestres y el consiguiente cese de la prestación del servicio en los siguientes supuestos. En cuanto a las infracciones graves, serán sancionadas con multa de 100.001 hasta 500.000 euros para servicios de comunicación audiovisual televisiva y de 50.001 a 100.000 para los radiofónicos, para los prestadores del servicio de comunicación electrónica y para los prestadores de servicio de catálogo de programas. Lo que sorprende es que en ningún momento se contempla -a diferencia de otras infracciones- que la reiteración de esta infracción conlleve sanciones como la revocación de la licencia para prestar el servicio de comunicación.

Por último, la Fiscalía ha tenido ocasión de pronunciarse sobre la materia en las Instrucciones 3/2005, de 7 de Abril, sobre las relaciones del Ministerio Fiscal con los medios de comunicación, y en la 2/2006, de 15 de Marzo, sobre el Fiscal y la protección del derecho al honor, intimidad y propia imagen de los menores. En la primera se señala de forma expresa que si los menores que intervienen como testigos en el proceso penal de adultos han de ser especialmente protegidos frente a publicidades perturbadoras, cuando se trate de menores sometidos al proceso especial de la LO 5/2000, de 12 de enero, reguladora de la Responsabilidad Penal de los Menores las restricciones para los medios de comunicación habrán de alcanzar su tonalidad más intensa. Declara y reconoce que la difusión a través de los medios de comunicación de la imagen o identidad del menor infractor trae consigo el riesgo cierto del etiquetaje del mismo como delincuente, con los devastadores efectos derivados de la estigmatización y con la correlativa puesta en peligro del objetivo de la reinserción. Considera que el posible interés informativo de la noticia cede, pues, ante la necesidad de protección de los intereses del menor afectado; y que no será por tanto aplicable al proceso de menores la jurisprudencia acuñada por el TC en materia de acceso de medios de comunicación a juicios orales penales. Sin embargo, concluye de igual forma que tales consideraciones no pueden llevar a postular un veto total o un apagón informativo sobre los procesos de

\footnotetext{
19 El artículo 7.2 de la Ley 7/2010 señala que "está prohibida la emisión en abierto de contenidos audiovisuales que puedan perjudicar seriamente el desarrollo físico, mental o moral de los menores, y en particular, programas que incluyan escenas de pornografía o violencia gratuita. El acceso condicional debe posibilitar el control parental. Aquellos otros contenidos que puedan resultar perjudiciales para el desarrollo físico, mental o moral de los menores solo podrán emitirse entre las 22 y las 6 horas, debiendo ir siempre precedidos por un aviso acústico y visual, según los criterios que fije la autoridad audiovisual competente. El indicador visual habrá de mantenerse a lo largo de todo el programa en el que se incluyan dichos contenidos. Asimismo, se establecen tres franjas horarias consideradas de protección reforzada tomando como referencia el horario peninsular: entre las 8 y las 9 horas y entre las 17 y las 20 horas en el caso de los días laborables y entre las 9 y las 12 horas sábados, domingos y fiestas de ámbito estatal. Los contenidos calificados como recomendados para mayores de 13 años deberán emitirse fuera de esas franjas horarias, manteniendo a lo largo de la emisión del programa que los incluye el indicativo visual de su calificación por edades. Será de aplicación la franja de protección horaria de sábados y domingos a los siguientes días: 1 y 6 de enero, Viernes Santo, 1 de mayo, 12 de octubre, 1 de noviembre y 6,8 y 25 de diciembre. (...)".
} 
menores. Tampoco cabe extraer la conclusión de que queda excluida la facultad del Fiscal de informar a la opinión pública. Por último, señala que en el proceso penal de menores también se dan casos de interés público y en los que cabe apreciar un legítimo interés por informar y por recibir información. Y por ello, en este proceso los datos y explicaciones suministrados por el Fiscal tendrán una especial utilidad social, teniendo en cuenta la desinformación y las explicaciones desenfocadas, -en ocasiones por simple desconocimiento- que se difunden con cierta frecuencia, y que origina en ocasiones una infundada zozobra, inquietud e incluso alarma social ${ }^{20}$. Finalmente, concluye que respetando los límites generales y los especiales que informan a este proceso, preservando en todo caso la identidad e imagen del menor, podrá proporcionarse cuando sea necesario una información suficiente acerca de hechos delictivos cometidos por menores y del desarrollo del proceso penal incoado. Y que obviamente, lo que no cabrá en ningún caso es la publicidad externa mediata del acto de la audiencia mediante la grabación de audio o video.

En la Instrucción 2/2006, de 15 de Marzo se vuelve a resaltar que el tratamiento informativo del menor debe inspirarse en el principio general de protección reforzada de sus derechos a la intimidad y a la propia imagen, y que en la ponderación a realizar necesariamente debe tenerse presente el superior interés del menor, que además y conforme al artículo 2 de la LO 1/1996 debe primar sobre cualquier otro interés legítimo que pudiera concurrir.

Desarrolla las líneas principales de lo que será el ejercicio de la legitimación legalmente acordada, considerando justificada la difusión de noticias de menores, cuando los hechos en los que se vea inmerso el menor sean asuntos públicos de interés, sin determinar concretamente cuáles pudieran ser los mismos, pero reiterando que siempre será con la adopción de las cautelas que en cada caso dicten las circunstancias para evitar que el mismo se vea perjudicado (no incluir el nombre ni la imagen, o distorsionar su rostro de modo que sea imposible su identificación, no aportar datos periféricos que puedan identificarlo, etc.). El problema radica ciertamente en el control de esas circunstancias que pueden identificarlo, más aún cuando el entorno en que acaecen los hechos es pequeño. Pese a esa declaración general, la Instrucción se centra en los delitos contra la libertad sexual para exigir un especial rigor a los Fiscales en cuanto a la preservación de la identidad de la víctima, cuando además de ser ésta menor de edad, los hechos investigados, enjuiciados o sentenciados se refieran a delitos contra la libertad sexual. Habrán de considerarse en estos supuestos antijurídicos no solo la identificación por nombre y apellidos de las víctimas menores y la captación de su imagen sino también la información sobre datos colaterales al menor que sean aptos para facilitar su identificación.

En todo caso, la Fiscalía General del Estado reconoce la extensa casuística que en la materia puede darse, concluyendo que habrá que estar al caso concreto, ponderando las circunstancias concurrentes, tomando como criterios generales los siguientes:

\footnotetext{
20 Considera que esta misma posición es postulada por la Recomendación (2003)20, de 24 de Septiembre del Comité de Ministros del Consejo de Europa sobre nuevas vías para el tratamiento de la delincuencia juvenil y el papel de la justicia juvenil en su punto VI.25.
} 
$1^{\circ}$. La difusión de la imagen de un menor en un medio de comunicación exige contar con el consentimiento del menor maduro o de sus representantes legales.

$2^{\circ}$. Aún contando con los preceptivos consentimientos, si la difusión de la identidad o de la imagen del menor puede considerarse contraria a sus intereses, la intromisión será en principio ilegítima.

$3^{\circ}$. No procederá en general el ejercicio de acciones por el Ministerio Fiscal ante emisión de programas o la publicación de fotografías en los que aparezcan menores, en actividades con dimensión pública tales como concursos, debates, musicales, actividades deportivas etc., siempre que las propias circunstancias que rodeen la publicación excluyan el perjuicio para los intereses de los mismos. Tampoco procederá en general el ejercicio de acciones por el Ministerio Fiscal ante la difusión de imágenes de menores en lugares públicos, cuando aparezcan de manera meramente casual o accesoria de la información principal y siempre que tales lugares o actos no presenten aspectos negativos.

$4^{\circ}$.Si la difusión casual o accesoria de la imagen del menor se vincula a lugares, personas o actos con connotaciones negativas, habrán de utilizarse técnicas de distorsión de la imagen para evitar que el mismo pueda ser identificado.

No obstante, el problema radica -como señalábamos- en la protección al menor infractor, que tiene unas características y condicionantes más marcados que la protección genérica a todo menor que se contempla en tales previsiones. Es en este ámbito donde la protección que dispensa nuestro sistema es escasa, ocasional y poco definida. Y pese a todo ello, la citada Instrucción $n^{0}$ 2/2006 termina con una conclusión que aún siendo adecuada, correcta y deseable, no deja de ser decepcionante a los efectos de una efectiva y adecuada protección del menor infractor, reconociendo que ni las vigorosas normas internacionales, estatales y autonómicas ya promulgadas, ni la supervisión de las Administraciones públicas, ni la decidida intervención del Ministerio Fiscal puedan garantizar un pleno y riguroso respeto a los derechos de los menores si no van acompañadas de una auténtica concienciación social que asuma la necesidad de una escrupulosa tutela frente a las intromisiones que puedan llegar a poner en riesgo o perturbar su proceso de maduración. Representantes legales, medios de comunicación, poderes públicos y sociedad en general, deben cada uno en su ámbito funcional constituirse en garantes de los derechos de los menores. Los profesionales y los medios de comunicación debieran sin reservas asumir ese principio deontológico. Es cierta la necesidad de una mayor conciencia social, pero la única alusión a ella sin que por los agentes especialmente llamados a hacer efectiva tal protección se tome partido decidido por actuar, no deja de ser -con todos los respetos y siendo consciente de la dificultad de la materia- un brindis al sol.

Recientemente, ante los últimos casos con trascendencia social y dado el interés que suscita la materia, la Fiscalía General del Estado ha vuelto sobre la cuestión en su Circular 9/2011, de 16 de Noviembre, limitándose a recordar las previsiones contenidas en las Instrucciones $\mathrm{n}^{\mathrm{o}} 3 / 2005^{21} \mathrm{y} \mathrm{n}^{\mathrm{o}} 3 / 2008^{22}$, sin dar un paso más en la profundización de la protección ni en reflexionar sobre posibles previsiones legislativas en la materia.

\footnotetext{
${ }^{21}$ Sobre las relaciones del Ministerio Fiscal con los medios de comunicación.
} 
Por último, resulta conveniente señalar que nuestro Tribunal Constitucional, en su STC 30/1982, se pronunció respecto a la publicidad de los juicios orales señalando "que el principio de la publicidad de los juicios, garantizado por la Constitución (art. 120.1), implica que éstos sean conocidos más allá del círculo de los presentes en los mismos, pudiendo tener una proyección general. Esta proyección no puede hacerse efectiva más que con la asistencia de los medios de comunicación social, en cuanto tal presencia les permite adquirir la información en su misma fuente y transmitirla a cuantos, por una serie de imperativos de espacio, de tiempo, de distancia, de quehacer, etc., están en la imposibilidad de hacerlo. Este papel de intermediario natural desempeñado por los medios de comunicación social entre la noticia y cuantos no están, así, en condiciones de conocerla directamente, se acrecienta con respecto a acontecimientos que por su entidad pueden afectar a todos y por ello alcanzan una especial resonancia en el cuerpo social, como ocurre indiscutiblemente con el desarrollo de la vista de la causa que nos ocupa. Consecuencia de ello es que, dadas las limitaciones de cabida del recinto, hubo de establecerse una selección en orden a la asistencia a la vista, concediéndose acreditaciones sobre la base de criterios objetivos. En este sentido, no resulta adecuado entender que los representantes de los medios de comunicación social, al asistir a las sesiones de un juicio público, gozan de un privilegio gracioso y discrecional, sino que lo que sé ha calificado como tal es un derecho preferente atribuido en virtud de la función que cumplen, en aras del deber de información constitucionalmente garantizado". En todo caso, en la actualidad, la cuestión se viene resolviendo a través de los correspondientes Gabinetes de Prensa y por la emisión de una señal institucional que permite ofrecerla a todos los medios que la solicitan y llevar a cabo una mayor e interesante protección de menores, víctimas y testigos.

\section{PROBLEMÁticA ACTUAL.}

A lo largo de los últimos años hemos asistido a prácticas informativas de dudosa licitud existiendo un acuerdo básico en doctrina y jurisprudencia sobre qué conductas de los medios de comunicación son abusivas al informar de la justicia. Nuestro Tribunal Constitucional ha tenido ocasión de pronunciarse al hilo de la presencia de las cámaras en las salas de audiencias ${ }^{23}$, los juicios paralelos ${ }^{24}$ y el secreto de sumario ${ }^{25}$, pero no así de forma expresa en cuanto a la efectividad de la protección del menor frente a los medios de comunicación.

Aún cuando a lo largo de la vigencia de la Ley de Responsabilidad Penal del Menor los supuestos de acciones delictivas graves cometidos por menores apenas han sido $\operatorname{casos}$ aislados ${ }^{26}$, y podríamos decir que excepcionales, aún cuando los medios de

\footnotetext{
${ }^{22}$ Sobre el Fiscal de Sala Coordinador de Menores y las secciones de menores.

${ }^{23}$ Vid. SSTC $56 / 2004$ y $57 / 2004$.

${ }^{24}$ Vid. SSTS $171 / 1990$ y $136 / 1999$.

${ }^{25}$ Vid. STC 13/1985.

${ }^{26}$ Los casos más celebres fueron el de José Rabadán (el asesino de la catana), las niñas de San Fernando, el caso de Sandra Palo y el reciente de Marta Del Castillo.
} 
comunicación transmitan a la sociedad una distorsionada imagen en cuanto a la habitualidad de dicho tipo de conductas, el tratamiento informativo de los mismos plantea serias dudas. Más aún, si atendemos a la normativa internacional y a los fines que persigue nuestro sistema penal de menores. Son muchas las cuestiones que de dicho tratamiento se pueden plantear, sobre las que cabe reflexionar en profundidad y alcanzar alguna conclusión en el ámbito jurídico en el que nos encontramos. En este sentido, podríamos destacar las siguientes:

$1^{\mathrm{a}}$. En todos los casos de acciones delictivas graves, sea de forma directa o indirecta, se ha desvelado la identidad del menor delincuente. Si atendemos a los fines que persigue la legislación penal de menores, dicha identidad debería preservarse cuidadosamente a lo largo del proceso, sin que ello suponga privarla del derecho ${ }^{27}$ que pueda tener a conocer la identidad de quien fue su agresor. Sin embargo, si examinamos los casos más relevantes podemos comprobar cómo han sido las propias víctimas y perjudicados por el delito cometido quienes posteriormente a su enjuiciamiento se han afanado en desvelar la identidad y las circunstancias del menor, pretendiendo con ello reparar el daño causado y su disconformidad con el tratamiento penal dispensado a los menores. Basta recordar el seguimiento de la familia de Sandra Palo a uno de los autores del crimen, “el Rafita”, tratando de difundir su imagen de forma constante y los hechos delictivos que pudiera ir cometiendo, como único medio de resarcir la insatisfacción del reproche penal recaído sobre los autores menores de edad. Con ello, asistimos a una nueva y constante victimización de las víctimas, y un ataque a la intimidad del menor, pudiendo afectar a los fines educativos de las medidas impuestas. El debate público se abre y se centra en casos como éste, en la disconformidad de la sociedad con la respuesta penal, obviando la condición de menor de edad del autor y la finalidad reeducativa y de reinserción del sistema, pretendiendo apartar y soslayar tales previsiones a favor de un concepto meramente retributivo por los hechos realizados. En todo caso, dado el corto espacio de tiempo en el que interviene la jurisdicción de menores -de 14 a 18 años- y el acceso a la mayoría de edad del menor, con lo que tal hecho conlleva en cuanto a autonomía personal y rebaja del nivel de protección de determinados derechos, en ese momento la preservación de su identidad y circunstancias familiares no ostentaría un fin de protección tan reforzado y específico como durante su etapa de minoría de edad.

\footnotetext{
${ }^{27}$ Resulta destacable que hoy por hoy el Estatuto de la víctima en el proceso penal recogido para el ámbito europeo en la Decisión Marco del Consejo de 15 de Marzo de 2.001 (DOCE, 22 de Marzo de 2.001) no configura un derecho de la víctima a conocer la identidad y circunstancias de su agresor. Lo más es que el artículo 4 contempla el derecho a recibir información, pero dicha información que se califica como pertinente para la protección de sus intereses, contempla unos mínimos entre los que no se recoge la identidad del acusado o agresor. Ciertamente pudiera incluirse en el desarrollo del proceso penal relativo al inculpado, pero no se configura expresamente el conocimiento de dicha identidad y circunstancias como derecho de la víctima. En todo caso, y sin duda alguna, la víctima tendrá conocimiento de circunstancias sobre la identidad de su agresor, sea por la denuncia inicial, por el desarrollo del proceso, la celebración del juicio o el dictado de la sentencia.
} 
En todo caso, esta actuación solo conllevará una sanción económica en el caso de que se realice por un medio de comunicación y se tramite el correspondiente procedimiento administrativo-sancionador ${ }^{28}$.

$2^{\text {a }}$. Los medios de comunicación buscan y persiguen la descripción detallada del “modus operandi” empleado, poniendo un desmedido énfasis en su descripción y en informar sobre todos y cada uno de los elementos que constituyen el mismo, aún cuando éste sea especialmente llamativo por la crueldad empleada. En ocasiones incluso, gracias a las nuevas tecnologías, al uso generalizado de móviles que permiten la captación y grabación de imágenes, a internet, y a las plataformas existentes para colgar vídeos y fotografías en la red ${ }^{29}$, con posibilidad de llegar en un breve espacio de tiempo a todo el mundo, los hechos delictivos son reproducidos de forma constante y reiterada en los medios de comunicación. Abren telediarios y programas informativos, centran debates y son reiteradas hasta la saciedad en programas de sucesos, siendo rescatadas y reproducidas cuando vuelven a producirse hechos similares. Es más, en ocasiones sirven de ejemplo a emitir o reiterar por otros menores, pues si ya puede ocurrir en el adulto, la personalidad del menor es más frágil a esa atracción de imitación, de conductas a las que se percibe que se les da un eco mediático y una popularidad realmente relevante, distorsionando sobremanera su propia antijuridicidad.

\footnotetext{
${ }^{28}$ Que según remite el artículo 55 de la Ley 7/2010 se tramitará conforme a lo dispuesto en el Capítulo II del Título IX de la Ley 30/1992, de 26 de noviembre, de Régimen Jurídico de las Administraciones Públicas y del Procedimiento Administrativo Común y su desarrollo reglamentario.

29 De especial interés en esta material resulta el artículo 16 de la Ley 34/2002, de 11 de julio, de servicios de la sociedad de la información y de comercio electrónico, dedicado a la responsabilidad de los prestadores de servicios de alojamiento o almacenamiento de datos, que al limitar la responsabilidad debilita las posibilidades de protección del menor ante hechos que utilicen estas vías:
}

"1. Los prestadores de un servicio de intermediación consistente en albergar datos proporcionados por el destinatario de este servicio no serán responsables por la información almacenada a petición del destinatario, siempre que:

a. No tengan conocimiento efectivo de que la actividad o la información almacenada es ilícita o de que lesiona bienes o derechos de un tercero susceptibles de indemnización, $o$

b. Si lo tienen, actúen con diligencia para retirar los datos o hacer imposible el acceso a ellos.

Se entenderá que el prestador de servicios tiene el conocimiento efectivo a que se refiere el párrafo a) cuando un órgano competente haya declarado la ilicitud de los datos, ordenado su retirada o que se imposibilite el acceso a los mismos, o se hubiera declarado la existencia de la lesión, y el prestador conociera la correspondiente resolución, sin perjuicio de los procedimientos de detección y retirada de contenidos que los prestadores apliquen en virtud de acuerdos voluntarios y de otros medios de conocimiento efectivo que pudieran establecerse.

2. La exención de responsabilidad establecida en el apartado 1 no operará en el supuesto de que el destinatario del servicio actúe bajo la dirección, autoridad o control de su prestador". 
$3^{\text {a }}$. La retransmisión del juicio por referencias de los intervinientes y de forma paralela a la celebración del juicio oral, donde los medios de comunicación realizan un desmesurado esfuerzo de cobertura para dar contenido a sus informativos y programas con todos los detalles del juicio oral, detalles que son recabados fuera de la audiencia y con los que persiguen y obtienen altas cuotas de audiencia.

La retransmisión de las sesiones de un juicio, sobre todo cuando de lo que se trata es del enjuiciamiento de hechos que por su notoriedad o por sus características de producción, comportan un alto grado de expectación social, constituye un factor decisivo para hacer del acto procesal un espectáculo mediático. Frecuentemente se manifiestan que los medios de comunicación refuerzan la apariencia de verdad en detrimento de la verdad, y la seducción en detrimento de la argumentación. Dicho fenómeno constituye un factor no desdeñable de presión, de alteración de las condiciones atmosféricas ideales en las que se debe desarrollar un proceso ${ }^{30}$. Nuestro Tribunal Constitucional en STC 57/2004, precisa con claridad los riesgos que, sobre el desarrollo del proceso conforme a todas las garantías reclamadas por la Constitución, pueden derivarse de la grabación y emisión de cámaras de las sesiones del juicio oral. El Alto Tribunal califica los efectos indeseables de intimidatorios (sic) sobre los procesados, sus defensores y los testigos. También destaca que en algunas circunstancias, la impresión de la realidad que va asociada a la imagen visual podría favorecer especialmente el desarrollo de los que se han denominado “juicios paralelos”, frente a los que la Constitución brinda un cierto grado de protección en la medida que pueden interferir el curso del proceso (ATC 165/1991; SSTC 136/99, 66/2001). Las consideraciones del Tribunal Constitucional patentizan con extremada claridad los intereses en juego: el desarrollo del proceso en condiciones que garanticen, junto a la regularidad en la producción de los medios probatorios, la imparcialidad del tribunal, o al menos la imagen de ésta, que constituye no sólo una garantía primaria del proceso justo del que son titulares las partes, en especial la persona acusada, sino el fundamento de la confianza de los ciudadanos en sus jueces ${ }^{31}$. De esta forma, debe valorarse en el

\footnotetext{
${ }^{30}$ Como de manera particularmente gráfica puso de relieve el Juez Clark, de la Corte Suprema de los Estados de Unidos, en la sentencia Estes $v$. Texas (hito jurisprudencial en esta materia siempre compleja de las relaciones entre intervención mediática y desarrollo del proceso penal), -el acusado que se juega su vida (valga su traslado simbólico a nuestra realidad) en un juicio tiene derecho que la cuestión se decida en un tribunal, no en un estadio ni en una ciudad o a lo largo del pais", afirmando, como ratio esencial de la decisión por la que se anulaba el juicio por lesión de la decimocuarta enmienda que garantiza la cláusula del proceso debido (due process), que el seguimiento televisado de las sesiones del juicio había tenido un efecto excesivamente configurador del proceso, generando prejuicios sociales contra el acusado que se habían proyectado entre los miembros del jurado.
}

\footnotetext{
${ }^{31}$ Así lo señala HERNÁNDEZ GARCÍA, J., en "84 Cuestiones sobre la dirección y publicidad del juicio oral". Consejo General del Poder Judicial, Madrid, 2011.
} 
proceso de adultos la pertinencia o no de la difusión del juicio oral ${ }^{32}$, resultando especialmente interesante la opción que los distintos Tribunales vienen haciendo por una señal única institucional que se suministra a todos los medios que están interesados en la misma, dado que con ello se evita que el juicio se distorsione y se centre en cuestiones accidentales o se trate de influir a través de la propia realización audiovisual del acto.

En el caso de los menores infractores la retransmisión en directo o diferido de la audiencia de enjuiciamiento resulta impensable, atendiendo a los principios que rigen en la jurisdicción, pero el proceso no se ve libre del juicio mediático paralelo, con numerosos periodistas acreditados, numerosas unidades móviles alrededor del Tribunal, con conexiones en directo constantes, y con entrada en toda la parrilla de programas de testimonios de personas que directa o indirectamente tienen participación en el proceso -sea como perjudicados, víctimas, familiares de las víctimas o acusados, letrados de las partes y público. Se reconstruye así sin pudor no sólo el mismo hecho justiciable sino la responsabilidad de las personas sometidas al proceso, presentándolas a la sociedad anticipadamente como culpables y desconociendo, en muchas ocasiones, el sufrimiento de las partes. En alguno casos muy recientes, como el enjuiciamiento del menor implicado en el llamado caso Marta del Castillo, el propio Ministerio Fiscal transmitía a la audiencia su versión y posición ante las pruebas que se iban practicado, circunstancia que si atendemos a la posición que éste ocupa en el proceso -por más que el legislador le atribuya el papel de protección del menor- no deja de ser una parte más, introduciendo con ello presiones y serias disfunciones al propio proceso y lo que nos resulta más importante, a la labor de protector del menor infractor que la propia ley le atribuye.

$4^{\text {a }}$. Por último, el desmesurado seguimiento en el tiempo de la noticia, ya que la atención se centra no sólo en el momento de la comisión del hecho, sino a lo largo de toda la instrucción de la causa, las medidas cautelares acordadas, el enjuiciamiento por parte del Juzgado de Menores, el desarrollo del posible internamiento en el Centro

\footnotetext{
${ }^{32}$ En este sentido resulta interesante destacar la regulación que realiza la legislación californiana, que en la regla 980 del Procedimiento Criminal del Estado establece 17 criterios que el juez debe tomar en cuenta para autorizar la capacitación de imágenes. Así, el juez deberá ponderar para autorizar la grabación de la audiencia pública: 1 . La necesidad de mantener la confianza y el crédito público en el sistema de justicia penal; 2. La importancia de promover el acceso del público al sistema judicial; 3. Tomar en cuenta el derecho a la confidencialidad y la privacidad de las partes; 4 . La naturaleza del caso; 5. El derecho a la privacidad de todos los partícipes (víctimas, testigos, jurados, abogados, fiscales); 6 . Los efectos sobre los menores; 7. Los efectos que pueden derivarse sobre el derecho de las partes a la elección de un jurado adecuado; 8. Los efectos sobre dudas o lagunas probatorias no resueltas; 9. Los efectos sobre decisiones procesales posteriores; 10 . Los efectos de la cobertura sobre la disposición de los testigos a cooperar o sobre su sentimiento de seguridad; 11 . Los efectos sobre el resto de los testigos que todavía no han declarado; 12 . El alcance de la cobertura sobre las condiciones de atención y concentración de los jurados; 13. La seguridad y dignidad del Tribunal; 14. El riesgo de interferencia con el funcionamiento de otras salas; 15 . El mantenimiento del orden de la Sala; 16. Las posibilidades técnicas y físicas de la Sala; y 17. Cualquier otro factor que el juez estime relevante.
} 
correspondiente, las incidencias en el cumplimiento de la medida -sean modificaciones, infracciones, etc...-, y en el tramo final, las dudas suscitadas en la opinión pública

De esta forma, la información que se transmite trata de hacer prácticamente imposible la posibilidad de reinserción del menor infractor, ya sea porque no consideren posible la misma por la capacidad excepcional de violencia puesta de manifiesto con los hechos cometidos, sea para mantener la alerta en la sociedad respecto a ese menor, ya convertido o en mayor, o finalmente porque sea la única posibilidad de que las víctimas del hecho se vean resarcidas del daño causado, lo que no evidencia más que una manifestación de la venganza del ofendido. En este sentido es llamativo examinar los medios de comunicación, y específicamente la red de internet para comprobar el rastro que todos y cada uno de los casos de delitos graves cometidos por menores han dejado y dejan, teniendo un pleno conocimiento de todos los hechos y circunstancias acaecidas desde la comisión del hecho hasta la fecha, su imagen, más o menos actual, hasta -por aproximación- su lugar actual de residencia. Tales circunstancias revelan como parece prevalecer la seguridad ciudadana, frente a la posibilidad legalmente reconocida de reinserción y de desarrollo de una vida social libre. Pero hoy por hoy, el rastro en internet de los menores que cometieron delitos graves se perpetúa en la red, en clara contradicción con los instrumentos internacionales y las previsiones legales que rigen en nuestro ordenamiento.

Por último, y en relación a las cuestiones ya destacadas y a la protección integral del menor infractor suscita seria preocupación el anuncio que recientemente ${ }^{33}$ ha hecho el Ministro de Justicia en su comparecencia ante la Comisión de Justicia del Congreso de los Diputados de que se propone reformar la LORPM para unificar la investigación y el enjuiciamiento en los casos de delito grave en los que estén implicados mayores y menores, sin que esto suponga una merma de los derechos del menor. Cabe destacar que la previsión actualmente existente en el artículo $16.5 \mathrm{LORPM}^{34}$ se refiere únicamente al Juez de Instrucción competente para el conocimiento de la causa, a fin de que tan pronto como compruebe la edad de los imputados, adopte las medidas necesarias para asegurar el éxito de la actividad investigadora respecto de los mayores de edad y ordenará remitir testimonio de los particulares precisos al Ministerio Fiscal, a los efectos prevenidos en la LORPM. No contempla previsión alguna respecto al enjuiciamiento conjunto ${ }^{35}$ de menor y adulto, enjuiciamiento que no podrá ver merma en las garantías y especialidades de la jurisdicción de menores, y especialmente en el hecho de que el Juez

\footnotetext{
${ }^{33}$ El pasado 25 de Enero de 2.012.

${ }^{34}$ Precepto respecto del que se solicitó por la acusación particular ejercida por los padres de Marta Del Castillo el planteamiento de una cuestión de inconstitucionalidad, siendo rechazada por auto de 22 de Marzo de 2.011 del Juzgado de Menores no 3 de Sevilla.

35 La reforma anunciada podría ir contra lo dispuesto en el artículo 40.3 de la Convención de los Derechos del Niño, en el artículo 10.2 del Pacto Internacional de Derechos Civiles y Políticos de 1.966, y de la Regla oo 2 de las Reglas de Beijing de 1.985.
} 
o Tribunal que lo realice debe estar formado por especialista. Esperemos que tal voluntad legislativa vaya acompañada de la decidida voluntad de introducir la especialidad en la segunda instancia, pues nuestro país infringe los instrumentos internacionales ratificados al contemplar la especialidad únicamente en la primera instancia, dándose la paradoja de que la apelación es objeto de Tribunales que no cuentan con la correspondiente especialidad en la materia.

Con todo, la oferta de los medios de comunicación para proteger al menor infractor y dar respuesta a las objeciones que se le realizan en la materia no deja de centrarse en un mero voluntarismo y en la formulación de Códigos Deontológicos que no centran la cuestión más en el campo de los propósitos, sin que la infracción de los mismos le conlleve perjuicio alguno, sino el beneficio de la audiencia y de los ingresos publicitarios consiguientes.

\section{CONCLUSIONES.}

Examinada la cuestión, la exigencia de una total protección del menor, y específicamente del infractor, que dimana no solo de las previsiones internacionales ratificadas por nuestro Estado y de la legislación aprobada sino de la propia jurisprudencia, concluimos que:

$1^{\circ}$. La sociedad de la información en la que vivimos superpone el interés informativo a la protección integral de los menores que puedan verse implicados en hechos graves con trascendencia penal.

$2^{\circ}$. Los medios de comunicación fomentan el desarrollo de juicios paralelos en los que el conocimiento no es completo en cuanto a los hechos y la información de los mismos, realizándose dicha valoración por la sociedad, sin que ésta tenga ya conocimientos jurídicos ni legales sino una mínima cultura judicial.

$3^{\circ}$. La labor que desarrollan los medios de comunicación en la actualidad afecta de lleno al principio constitucional de presunción de inocencia, presentando al denunciado o acusado como culpable de unos hechos que se reiteran permanentemente durante un importante período temporal y que se dan por probados, por el mero hecho de enunciarlos, sin que quepa prueba de descargo alguna. Es más, incluso el dictado de una posterior sentencia absolutoria no restablecerá el daño causado a la presunción de inocencia.

$4^{\circ}$. El desarrollo de las plataformas de comunicación, a través de su difusión por internet, perpetúa en el tiempo los ataques que a la identidad y circunstancias de la persona, sea adulta o menor, y a su presunción de inocencia se realizan. 
$5^{\circ}$. La posibilidad de respuesta ante tales ataques y vulneraciones a los menores infractores resulta mínima, quedando en el ámbito administrativo y atribuyéndose al Ministerio Fiscal, quien reúne también la condición de instructor y acusador de dicho menor infractor, y se rige por principios de oportunidad, como señalábamos.

Por todo ello, dada la situación actual, y si queremos hacer realidad los principios que declaramos y los convenios internacionales que ratificamos, nuestras recomendaciones al legislador serían las siguientes:

$1^{\text {a }}$. En el ámbito del menor infractor que se ve inmerso en un proceso penal los poderes públicos deben ser totalmente inflexibles en cuanto a las conductas que conduzcan a la identificación pública del menor, sea su identidad o imagen, o a sus circunstancias familiares.

$2^{a}$. Deben adoptarse instrumentos más preventivos y eficaces para evitar la infracción de la protección que reclamamos, sea por el endurecimiento de las sanciones administrativas -tanto económicas como la previsión de la retirada de la oportuna licencia por infracciones graves o reiteradas, que ahora se elude para estos casos- o por la tipificación penal de las conductas más reprochables. No se trata de mermar el derecho a la información o a la libre expresión sino de optar por el interés superior del menor y la protección del proyecto educativo diseñado para su reinserción social y reeducación.

$3^{\text {a }}$. Sería conveniente plantear la atribución del papel protector del menor infractor y la legitimación para instar su protección a una institución ajena al Ministerio Fiscal, que desempeña en el proceso penal de menores el papel de instructor y de acusador del propio menor cuya protección pretende amparar. Quizás una solución sería reservar esa posición para el Fiscal de Protección, lo que sería objetable en aquellas Fiscalías que tienen atribuidas las funciones de protección a las Secciones de Menores infractores.

$4^{\text {a }}$. Cada vez resulta más perentorio que el legislador se decida a dotar de efectiva regulación ${ }^{36}$ y protección la previsión constitucional de la presunción de inocencia, tan afectada por la labor informativa de algunos medios ${ }^{37}$.

\footnotetext{
${ }^{36}$ Como ejemplo cercano tenemos la Ley francesa № 2000-516, de 15 de Junio de 2000, destinada a reforzar la presunción de inocencia y los derechos de las víctimas.

${ }^{37}$ Ejemplo ilustrativo de tal daño fue en nuestro país el caso de Diego Pastrana, que tras el fallecimiento de su hijastra de 3 años en Tenerife el 27 de Noviembre de 2.009 fue acusado, basándose en la opinión de un médico, por ello. Todos los medios de comunicación se hicieron eco de ello dándolo como autor de la muerte, sin hacer referencia a su condición de presunto autor, terminando por determinarse que falleció por una caída sin responsabilidad del mismo. Aun cuando los medios rectificaron el daño moral fue irreparable.
} 
5a. Por último, consideramos que por la alta relevancia constitucional que comporta el régimen de publicidad externa del proceso penal mediante la intervención de medios de comunicación, la intervención legislativa en esta materia se torna ya indispensable en nuestro Derecho.

\section{BIBLIOGRAFIA}

AZURMENDI, Ana. "La información sobre menores delincuentes y sus procesos judiciales”. En: EGÚZQUIZA, I. y VIDAL, V., La información judicial. Valencia: Coso, 2008. p. 201-219

BACH FABREGÓ, R. y OTROS. “84 Cuestiones sobre la dirección y publicidad del juicio oral”. Consejo General del Poder Judicial, Madrid, 2011.

BOUZA, F. "La influencia de los medios en la formación de la opinión pública: los procesos jurídicos y los juicios paralelos. En CONSEJO GENERAL DEL PODER JUDICIAL, Justicia y medios de comunicación. Madrid: Consejo General del Poder Judicial, 2007. p. 35-59

CONDE ZABALA, M.J. "El nuevo sistema de justicia penal juvenil en España”. En: GARCÍA MÉNDEZ, E. y OTROS, Adolescentes y responsabilidad penal. Buenos Aires (Argentina): Editorial Ad Hoc, 2001. p. 135-156

LÓPEZ ORTEGA, J.J.“Información y justicia. (La dimensión constitucional del principio de publicidad judicial y sus limitaciones). En CONSEJO GENERAL DEL PODER JUDICIAL, Justicia y medios de comunicación. Madrid: Consejo General del Poder Judicial, 2007. P. 93-135

MARTÍNEZ GUERRA, A. "El tratamiento de los casos judiciales en la prensa. Calumnias, injurias y juicios paralelos”. Noticias jurídicas, 2002 http://noticias.juridicas.com/articulos/00-Generalidades/2002088561320710222311.html

RIVERO HERNÁNDEZ, F. “El interés del menor”. Editorial Dykinson. Madrid, 2000 